\title{
The Neuropsychiatry of the Parietal Lobe: Clinical Manifestations of Integrated Neural Networks in Everyday Practice
}

\author{
By Eric Hollander, MD
}

I hope that our readers are enjoying a much deserved summer season, and that all of us can mix meaningful work with some time out for enjoyment of nature, family, and recreation. Whether relaxing at the beach or in the country, we hope that reading this month's CNS Spectrums may enlighten you to a deeper appreciation of the role of the parietal lobes and related structures in various neuropsychiatric phenomena, especially spatial abilities, consciousness, and body image.

I would like to thank Michael Trimble, MD, FRCP, FRPsych, for guest editing this issue. Also, Dr. Trimble will be launching a new column series called "Brain Regions of Interest" later this year. The basic idea is to highlight specific brain regions or integrated brain networks of interest, and to describe, in a practical fashion, to a general neuropsychiatric audience why these systems are important; how they function; what role they serve; and how their dysfunction results in clinical symptoms and illness.

Neurologists have substantial training and appreciation for the impact of localized lesions on the development of clinical phenomena. Psychiatrists clearly have less training and appreciation of this, and are more focused on interventions that might improve clinical symptoms and functional status. Nevertheless, a concise review of these issues can be valuable for all practitioners.

For example, it is well known that the parietal lobes play a role in spatial functioning. However, it is less well known that specific clinical syndromes are linked to dysfunction of the parietal lobes, and that the function of the parietal lobes can best be understood when viewed as functionally integrated networks with other regions, such as the frontal lobes. Also, the precuneus has been much in the news of late, specifically with regards to its role in consciousness. The precuneus seems to exist in a "default mode" of brain function during the conscious resting state, and is selectively deactivated in various conditions that impair consciousness. It is also known that the parietal lobes play a role in the perception of body image, but it is less well known that the parietal lobes influence both the visual and mental image that we have of our bodies, or how we see ourselves when we view ourselves in a mirror.

Also in this issue, Alzbeta Juven Wetzler, MD, and colleagues report an unusual case of obsessive-compulsive disorder (OCD) sequelae following a suicide attempt, illustrating the relationship between stress and OCD. The authors highlight not only the existence of "posttraumatic obsession" but also the importance of accurate interpretation of suicidal preoccupation leading to the diagnosis of OCD, rather then suicidal ideation secondary to depression.

Finally, Maria C. Rosário, MD, PhD, and colleagues describe a pilot study of escitalopram in OCD. Despite the small sample size and the openlabel nature of the trial, the data suggest that escitalopram may be a useful option for patients with OCD. It should be noted, however, that this medication does not have Food and Drug Administration approval for OCD in the United States.

This issue describes specific brain regions that play a role in some of the most fundamental symptoms of human experience, that of consciousness, spatial ability, and body image. It then describes an unusual development of OCD following suicidal trauma, and a pilot study of a non-FDA-approved treatment for such symptoms. Enjoy your summer. CNS

Dr. Hollander is the editor of this journal, Esther and Joseph Klingenstein Professor and Chairman of Psychiatry at the Mount Sinai School of Medicine, and director of the Seaver and New York Autism Center of Excellence in New York City. 


\section{Brief Summary of Prescribing Information}

\section{ROZEREMTH}

(ramelteon) Tablets

MDICATIONS ANO USAGE

ROZEAEM is indicated for the treatment of insomnia characterized by dificulty with sleep ons

conTranolCations

ROZEREM is contraindicated in pattents with a hypersensitivity to ramelteon or any components of the ROZEREM formulation.

MARanines

Since sleep disturbances may be the presenting manifestation of a physica and/or psychiatric disorder, symptomattc treatment of insomnia should be remit after a reasonable period of treatment may indicate the presence of a primary psychiatric and or medical illness that should be evaluated. Worsenting may be the result of an unrecognized underlying psychiatric or physical disorder and requires turther evaluation of the patient. As with other hypnotics exacertation of insomita and emergence of cognittive and behavioral abnor-
malittes were seen with ROZZREM during the clinical development program. ROZEREM should not be used by patients with severe hepatic impairment. ROZEREM should not be used in combination with fluvoxamine (see

A variety of cognilive and behaviof changes have been reported to occur in assoclation with the use of hypnotics. In primarily depressed patients,
worsening of depression, including suicidal ideation, has been reported in

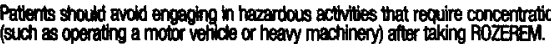
Aftor taking ROZEREM, patients should confine their activities to those After taking ROZEREM, patients

\section{PRECAUTIONS}

Conoral

Oezen not been studled in subjects with severe sleep apnea or Pation Patients should be advised to
combination with ROZEREM

Ise in Adolescents and Chidron

ROZEREM has been associated with an effect on reproductive homones in adults, e.g., decreased testosterone levels and increased prolactin levels. It is may have on the reproductive axis in developing humans (see Pediatic Uee). thormation for Patients

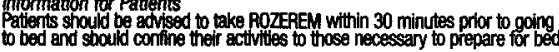
Patients should be advised to avold engaging in hazardous activities (such Patients should be advised that they should not take ROZEREM with or

Patients should be advised to consult their health care provider if they
experlence worsening of Insomnia or any new behavioral signs or

Patients should consult their health care provider if they experience one of
the fotlowing: cessaton of menses or galactorthea in temales, decreased Laboratory Tests

ing is required.

For patients presenting with unexplained amenomhea, galactorntea, decreased libldo, or problems with fertility, assessment of prolactin levels Dry Interection

OZZFEM has a hilghy variable intersubject pharmacokinetic profile (approx mately $100 \%$ coefficient of variation in $C_{\text {max }}$ and AUC). As noted above,
$C Y P 1 A_{2}$ is the major isozyme involved in the metabolism of ROZZREM; the CYP2C subtamily and CYP3A4 isozymes are also involved to a minor degree. Effects of Other Drugs on ROZEAEM Metabolism

Fuvoxamine (strong CYP1A2 inhtbitor): When fluvoxamine $100 \mathrm{mg}$ twice daily was administered for 3 days prior to single-dose co-administration
ROZEAEM $16 \mathrm{mg}$ and fluvoxamine, the AUC Co-int for ramelteon increased approximately is is fold , and the $C_{\text {max }}$ increased approximately 70 -fold, n combination with fluvaxamine (see WARAliniGS). Other less potent CYP1A2 inhibitors have not been adequately studied. ROZEREM should be adm
istered with caution to patients taking less strong CYP1A2 inhibitors. Rifampin (strong CYP enzyme inducer): Administration of rifampin $600 \mathrm{~m}$ once daily for 11 days resulted in a maan decrease of approximately $80 \%$
$(40 \%$ to $90 \%$ in total exposure to ramelteon and metabolite $M-11$, (both AU $C_{0-1}$ and $C_{m}$ ) after a single $32 \mathrm{mg}$ dose of ROZEFEM. Efficacy may be reduced when HOZEREM is used in combination with strong CYP enzyme Ketoconazole (strong CYP3A4 inhibitor): The AUC $C_{0-1 m}$ and $C_{\text {max }}$ of ramelteon increased by approximately $84 \%$ and $36 \%$, respectively, when a single $16 \mathrm{mg}$ dose of ROZEREM was administered on the fourthi day of ketoconazole
$200 \mathrm{mg}$ twice dally administration, compared to administration of ROZEREM alone. Similar increases were seen in M-ll pharmacokinetic variables.
R0ZEREM should be administered with caution in subjects taking strong
CYP3A4 inhibitors such as ketoconazole.

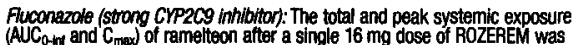
(AUC $C_{a i n}$ and $C_{\text {max }}$ of rameltson after a single $16 \mathrm{mg}$ dose of ROZEREM w
increased by approximately $150 \%$ when administered with fluconazole. increased by approximately $150 \%$ when administered with fluconazole.
Similar increases were also seen in $M$ - 11 exposure. ROZEREM should be administered with Interaction studies of concomitant administration of ROZEREM with fluoxetin
(CYP2D6 Inhibitor), Omeprazole (CYP1A2 inducer/CYP2C19 inhibitor),

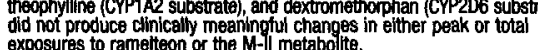
Molism of Other Drugs

Concomitant administration of ROZEREM with omeprazole (CYP2C19 substrate), dextromethorphan (CYP2D6 substrate), midazolam (CYP3A4

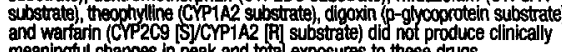
meaningtul changes in peak and total exposures to these drugs.

\section{Effoct of Acohol on Rozerem}

Abonol: Wut singla-dose, daytime co-administration of ROZEREM $32 \mathrm{mg}$ and alcohd ( $0.6 \mathrm{~g} / \mathrm{kg}$, there wore no clinically meaningul or statistically significant
effects on peak or total exposure to ROZEREM. However an additive effect was seen on some measures of psychomotor performance (i.e, the Digit Symbol Substitution Test, the Psychomotor Vigllance Task Test, and a Visual Analog
Scale of Sedaton) at some post-dosel time points. No additive effect was seen on the Delayed Word Recognition Test. Because alcohol by itself impairs pertormance, and the intended effect of ROZEREM is to promote sleeg
patients should be cautioned not to consume alcohol when using ROZEREM.
Drug/Laboratory Test Interactions tests. In addition, in vitro data indicate that ramelteon does not cause cannabinoids, or amphetamines in two standard urine drug screening methods in vitro.

Carcinogenesls, Mutagenesls, and Impairment of Fertllity Carcinogenesis

a two-year carcinogenicity study, $\mathrm{B}^{\mathrm{C}} \mathrm{C}_{3} \mathrm{~F}_{1}$ mice were administered Male mice exhibited a dose-related increase in the incidence of hepatic tumors at dose levels $\geq 100 \mathrm{mg} / \mathrm{kg} / \mathrm{day}$ inciuding hepatic adenoma, hepatic carcinoma, and hepatoble the and hepatic carcinoma at the $1000 \mathrm{mo} / \mathrm{kg} / \mathrm{day}$ dose level. The 00 -fitectleve for hepatic tumors in male mice was $30 \mathrm{mg} / \mathrm{kg} /$ day (103-times and 3 -imes the therapeutic exposure to ramelteon and the active metabolite $M-11$, an area under the concentration-time curve [AJC] comparison]. The no-effect level for hepatic tumors in female mice was $100 \mathrm{mg} / \mathrm{kg} / \mathrm{day}$ (827-times and 12-times the therapeutic MRHD based on AUC)

In a two-year carcinogenicity study conducted in the Sprague-Dawley rat, 250 or $1000 \mathrm{mg} / \mathrm{kg} / \mathrm{day}$ by oral gavage. Male rats exhibited a dose-relate increase in the incidence of hepatic adenoma and benign Leydig cell tumo of the testis at dose levels $\geq 250 \mathrm{mg} / \mathrm{kg} /$ day and hepatic carcinoma at the
$1000 \mathrm{mg} / \mathrm{kg} /$ day dose level. Female rats exfibited a dose-related increase in the incidence of hepatic adenoma at dose levels $\geq 60 \mathrm{mg} / \mathrm{kg} /$ /day and hepatic carcinoma at the $1000 \mathrm{mg} / \mathrm{kg} /$ day dose level. The no-efted $60 \mathrm{mg} / \mathrm{kg} / \mathrm{day}(1,429$-times and 12 -times the therapeutic exposure to rametteon and M-1I, respectively, at the MRHD based on AUC The no-effect level for hepatic tumors in female rats was $15 \mathrm{mgkg} /$ /day (4)2-times and the MRHD based on AUC)

The development of hepatic tumors in rodents following chronic treatment with non-genotoxic compounds may be secondary to microsomal enzyme induction, a mechanism for tumor generation not thought to occur in humans Leydig cell tumor development following treatment with non-genotoxic testosterone levels with compensatory increases in luteinizing hormone release, which is a known proliferative stimulus to Leydig cells in the Iuteinizing hormone than human Leydig cells. In mechanistic studies
long conducted in the rat daily ramelteon administration at 250 and $1000 \mathrm{mg} / \mathrm{kg} / \mathrm{day}$ for 4 weeks was associated with a reduction in plasm testosterone levels. In the same study, luteinizing hormone levels were elevated over a 24 -hour period after the last ramelteon treatment; howeve the durability of this lutenizing hormone finding and its support
proposed mechanistic explanation was not clearly established.

Athough the rodent tumors observed following ramelteon treatment occurred at plasma levels of rametteon and M-ll in excess of mean clinical plasma concentrations at the MRHD, the relevance of both rodent
tumors and benign rat Leydig cell tumors to humans is not known.

Mutagenesis

Ramerteon was not genotoxic in the following: in vitro bacterial reverse mutation (Ames) assay; in vitro mammalian cell gene mutation assay DNA synthesis assay in rat hepatocytes; and in in vivo micronucleus assays conducted in mouse and rat. Ramelteon was positive in the presence of $\$ 9$ metabolic activation.

Separate studies indicated that the concentration of the M-II metabolite formed by the rat liver $\mathbf{S 9}$ fraction used in the in vitro genetic toxicology therefore, the genotoxic potential of the $M-1 /$ metabolite was also assessed in these studies.

Impairment of Fertility

initial fertility and early embryonic deveropment study at dose levels of 6 . 60 , or $600 \mathrm{mg} / \mathrm{kg} / \mathrm{day}$, No effects on male or female mating or fertility wer observed with a ramelteon dose up to $600 \mathrm{mg} / \mathrm{kg} / \mathrm{day}$ ( 786 -times higher
than the MRHD on a $\mathrm{mg} / \mathrm{m}^{2}$ basis). Iregular estrus cycles, reduction in the number of implants, and reduction in the number of live embryos were
noted with dosing females at $\geq 60 \mathrm{mg} / \mathrm{kg} /$ day $(79$-times higher than the noted with dosing females at $\geq 60 \mathrm{mg} / \mathrm{kg} /$ day $(79$-times higher than the
MRHD on a $\mathrm{mg} / \mathrm{m}^{2}$ basis). A reduction in the number of corpora lutea occurred at the $600 \mathrm{mg} / \mathrm{kg} /$ day dose level. Administration of ramelteon up $600 \mathrm{mgkg}$ /day to male rats for 7 weeks had no effect on sperm quality and no effect on implants or embryos. In a repeat of this study using oral administration of ramelteon at 20,60 or $200 \mathrm{mg} / \mathrm{kg} /$ day for the same study duration females demonstrated irregular estrus cycles with doses $\geq 60 \mathrm{mgkg} / \mathrm{kay}$, bu no effects were seen on implantation or embryo viability. The no-effect dose
for fertility endpoints was $20 \mathrm{mo} / \mathrm{kg} /$ day in females (26-times the MRHD on a mg/m2 basis) and $600 \mathrm{mg} / \mathrm{kg}$ /day in males (786-times higher than the MRHD on a $\mathrm{mg} / \mathrm{m}^{2}$ basis) when con

Ramelteon has been shown to be a developmental teratogen in the rat When given in doses 197 times higher than the maximum recommended controlled studies in preanant women pregnancy only if the potential benefit justifies the potential risk to the fetus The effects of ramelteon on embryo-fetal development were assessed in gavage at doses of $0,10,40,150$, or $600 \mathrm{mg} / \mathrm{kg} /$ day during gestation days maternal toxicity and fetal teratogenicity was observed at doses greater by decreased body weight and, at $600 \mathrm{mg} / \mathrm{kg}$ /day, ataxia and decreased spontaneous movement. At matemally toxic doses $(150 \mathrm{mg} / \mathrm{kg} / \mathrm{day}$ or greater), the fetuses demonstrated visceral malformations consisting of (irregularly shaped scapula). At $600 \mathrm{mg} / \mathrm{kg} / \mathrm{day}$, reductions in fetal body weights and malformations including cysts on the external genitalia were additionally observed. The no-effect level for teratogenicity in this study was exposure to ramelteon and the active metabolite M-ll, respectively, at the $M R H D$ based on an area under the concentration-time curve [AUC]

comparison). Pregnant rabbits were administered ramelteon by oral gavage
at doses of $0,12,60$, or $300 \mathrm{mg} / \mathrm{kg} /$ day during gestation days $6-18$, which is the period of organogenesis in this species. Although maternal toxicity was apparent with a ramelteon dose of $300 \mathrm{mg} / \mathrm{kg} / \mathrm{day}$, no evidence of fetal effects or teratogenicity was associated with any dose level. The no-efiect level or teratogenicty was, therefore,
and 99-times higher than the therapeutic exposure to ramelteon and $M-11$,
respely, at the MRHD based on AUC).

The effects of ramelteon on pre- and post-natal development in the rat were studied by administration of ramelteon to the pregnant rat by oral gavage at doses of $0,30,100$, or $300 \mathrm{mg} / \mathrm{kg} /$ day from day 6 of gestation through weaned. Matemal toxicity was noted at doses of $100 \mathrm{mg} / \mathrm{kg} / \mathrm{day}$ or grand weight. Reduced body weight during the post-weaning period was also noticed in the offspring of the groups given $100 \mathrm{mg} / \mathrm{kg} /$ day and develomental delayed acquisition of the righting reflex, and an alteration of emotiona response. These delays are often observed in the presence of reduced

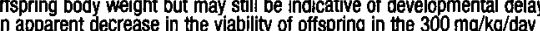
roup was likely due to aitered maternal behavior and function observed at this dose level. Offspring of the $300 \mathrm{mg} / \mathrm{kg} / \mathrm{day}$ group also showed evidence of diaphragmatic hernia, a finding observed in the embryo-feta reproductive capacity of offspring and the resulting progeny were not different from those of vehicle-treated offspring. The no-effect level for pre- and post-natal development in this studicy
higher than the MRHD on a $\mathrm{mg} / \mathrm{m}^{2}$ basis).

Labor and Delivery

The potential effects of ROZEREM on the duration of labor and/or delivery, no established use in labor and delivery.

Nursing Mothers

Ramelteon is secreted into the milk of lactating rats. It is not known mothers have been performed. The use of ROZEREM in nursing mothers is not recommended.

Pedlatric Use

Safety and effectiveness of ROZEREM in pediatric patients have not been may be used safely in pre-pubescent and pubescent patients.

Geriatric Use

A total of 654 subjects in double-blind, placebo-controlled, efficacy trials 75 years of age or older. No overall differences in safety or efficacy were observed between elderly and younger adult subjects.

ADVERSE REACTIONS

The data described in this section refect exposure to ROZFEM in 4251 subjects, including 346 exposed for 6 months or longer, and 473 subjects for one year.

Adverse Reactions Resulting in Dlscontinuation of Treatment Studies discontimued treatment owing to an adverse event, compared with $2 \%$ of the 1370 subjects receiving placebo. The most frequent adverse events leading to disccontinuation in subjects receiving ROZEREM were somnolence $(0.8 \%)$, dizziness $(0.5 \%)$, nat
headache $(0.3 \%)$, and insomnia $(0.3 \%)$.

ROZEREM Most Commonly Observed Adversa Events in Phase 1-3 trals

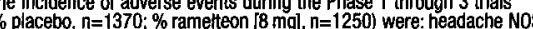
$(7 \%, 7 \%)$, somnolence $(3 \%, 5 \%)$, fatigue $(2 \%$, $4 \%)$, dizziness $(3 \%, 5 \%)$, nausea $(2 \%, 3 \%)$, insomnia exacerbated (2\%, $3 \%)$, upper respiratory tract
infection NoS (2\%, 3\%), diarthea NOS $(2 \%, 2 \%)$, myaliaia $(1 \%, 2 \%)$, depression $(1 \%, 2 \%)$, dysgeusia $(1 \%, 2 \%)$,
$(0,1 \%)$, blood cortisol decreased $(0,1 \%)$.

Because clinical trials are conducted under widely varying conditions, adverse reaction rates observed in the clinical trials of a drug cannot be directly compared to rates in clinical trials of other drugs, and may not clinical trials does, however, provide a basis for identitying the adverse DRUG ABUSE AND DEPENDENCE
ROZEREM is not a controlled Substance.

Human Data: See the CLINICAL TRIALS section, Studies Pertinent to Safety Concerns for Sleep-Promoting Agents, in the Complete

Animal Data: Ramefteon did not produce any signats from animal behavioral nudies indicating that the drug produces rewarding effects. Monkeys did piace preference in rats. There was no generalization between ramelteon and midazolam. Ramelteon did not affect rotorod performance, an indicator of disruption of motor function, and it did not potentiate the ability of diazepam to interfere with rotorod performance.

Discontinuation of ramelteon in animals or in humans after chronic administration did not produce withdrawal signs. Ramelteon does not appear to produce physical dependence.

OVERDOSAGE

So cases of Ryomptoms ROZEREM was administered in single doses up to $160 \mathrm{mg}$ in an abuse

Recommended Treatment
General symptomatic and supportive measures should be used, along with immediate gastric lavage where appropriate. Intravenous fluids should be administered as needed. As in all cases of drug overdose, respiration, pulse, general supportive measures employed.

Hemodialysis does not effectively redice exposure to ROZEREM. Therefore, Poison Control Center

swith the management of all overdosage, the possibility of multiple drug ingestion should be considered. The physician may contact a poison cont
center for current information on the management of overdosage.

Rx only

Manufactured by:

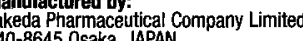

Maka, JAPAN

Manufachured in:

Kilruddery, County Wicklow, Republic of Ireland

Marketed by:

maceuticals America, inc

One Takeda Parkway

ROZEREM ${ }^{T M}$ is a trademark of Takeda Pharmaceutical Company Limited

2005, Takeda Pharmaceuticals America, Inc.

05-1124

Revised: Apr., 2006 